\title{
Original Article \\ Renal function in late survivors of Iranian children with cancer: Single centre experience
}

\author{
Arjmandi-Rafsanjani K, Hooman N1', Vosoug P \\ Departments of Pediatric Hemat-Oncology and 'Pediatric Nephrology, Ali Asgar Children's Hospital, \\ Iran University of Medical Sciences, Tehran, Iran.
}

Correspondence to: Dr. Nakysa Hooman, E-mail: hakiwa@iums.ac.ir

\begin{abstract}
CONTEXT: One of the side-effects of chemotherapy is nephrotoxicity, whose incidence rate has reportedly been higher in pediatrics. Early diagnosis of renal dysfunction may decrease the morbidity in those with partial or complete remission by avoiding nephrotoxic agents and promoting regular follow-up. AIMS: We studied the frequency of renal dysfunction in pediatric patients whose therapy was completed regardless of the type of chemotherapy. SETTINGS AND DESIGN: Prospective cross sectional study in Hematoncology department of children's hospital. MATERIALS AND METHODS: One hundred and eight pediatric cancer patients (44 females, 64 males), who were at least one year off therapy, enrolled in the study from 2003 to 2005. Demographic data, mean dosages of anticancer drugs, history of other nephrotoxic agents, nephrectomy, radiotherapy and acute renal failure were recorded. Fasting blood and urine samples were collected to calculate fractional excretion of magnesium, calcium, phosphate, urine protein to urine creatinine ratio, creatinine clearance (using Schwartz formula), urine analysis, urine osmolality and blood gas analysis. STATISTICAL ANALYSIS USED: T-test, Chi square and binary logistic regression were used to compare means, frequency and correlation respectively. $P$ values < 0.05 were considered significant. RESULTS: Renal dysfunction was seen in $25.2 \%$ of cases. These abnormalities included hypercalciuria (7.2\%), phosphaturia (13.5\%), magnesuria (3.6\%), glomerular filtration rate less than $90 \mathrm{ml} / \mathrm{min}(7.5 \%)$, metabolic acidosis $(3 \%)$, metabolic alkalosis $(10 \%)$, urinary concentration defect $(19 \%)$, proteinuria $(7.2 \%)$, glycosuria $(2 \%)$, microscopic hematuria (4\%), sterile pyuria (6\%), and hypertension (8\%). We found only Procarbazin as an independent variable of nephrotoxicity $(P<0.05)$. CONCLUSIONS: Mild to moderate tubular dysfunction has been observed in the survivors of cancer disease.
\end{abstract}

Key words: Cancer, chemotherapy, late survivors, nephrotoxicity, tubular dysfunction

\section{Introduction}

Although it improves the survival of children with cancer, chemotherapy is accompanied by late side-effects including organ dysfunction, second malignant neoplasm and adverse psychological sequelae. Tubular dysfunction, hypertension, renal failure, and bladder fibrosis have been reported as the predominant sequelae of radiotherapy, and Platinum, I fosfamide, or M ethotrexate chemotherapy. ${ }^{[1-6]}$ Young age during treatment, higher cumulative doses, concurrent nephrotoxins administration, previous unilateral nephrectomy, and pre-existing renal impairment are listed as potential risk factors of nephrotoxicity. ${ }^{[7-16]}$ We studied the frequency of nephrotoxicity in pediatric patients whose therapy was completed with no regard to the type of chemotherapy.

\section{Materials and Methods}

O ne hundred and eight ( 64 male, 44 female) children aged two months to 15 years old at the time of diagnosis of neoplastic disease, in whom therapy was discontinued for at least one year, enrolled in a prospective cross sectional study in the oncology department of our hospital from 2003 to 2005. Informed consent was taken from patients or parents.

All information about demographic data, recurrence of disease, cumulative doses of anticancer drugs, tumor 
lysis syndrome, history of nephrectomy (predominantly in Wilms' tumor), radiotherapy, and other nephrotoxic antibiotics (including A minoglycoside, Amphotericin B, Vancomycin, Acyclovir) were recorded. A complete physical examination was done and blood pressure was checked by standard sphygmomanometer. Blood pressure levels above 95\% were defined as hypertension, using the Task Force normogram for age and height. Fasting blood and urine samples were sent to a laboratory to calculate the fractional excretion of calcium $\left(\mathrm{FE}_{\mathrm{Ca}}\right)$, magnesium $\left(F E_{M g}\right)$, phosphate $\left(F E_{p h}\right)$, urine protein to creatinine ratio $(\mathrm{U} / \mathrm{U} / \mathrm{Cr})$, and glomerular filtration rate (GFR) (using Schwartz formula). U rine analysis was performed to detect glycosuria, albuminuria, hematuria or pyuria; fasting urine specific gravity and urine osmolality was used to detect urinary concentration ability. Heparinized blood samples were taken for blood gases. Renal sonography was performed in all cases.

Nephrotoxicity was defined by the presence of hypertension, hypercalciuria ( $\mathrm{FE}_{\mathrm{Ca}}>5 \%$ ), hypermagnesuria $\left(\mathrm{FE}_{\mathrm{Mg}}>4 \%\right)$, phosphaturia $\left(\mathrm{FE}_{\mathrm{Ph}}>25 \%\right)$, diluted urine (urine osmolality $<350 \mathrm{mosol} / \mathrm{kg} / \mathrm{H}_{2} \mathrm{O}$ and specific gravity $<1.015)$, acidosis $(\mathrm{PH}<7.35$ and $\mathrm{HCO} 3<20)$ or alkalosis ( $\mathrm{PH}>7.45$ and $\mathrm{HCO} 3>26$ ), proteinuria (UP/U Cr $>0.2$ and positive dipstick for albumin), GFR $<90 \mathrm{ml} / \mathrm{min} / \mathrm{m}^{2}$, or glycosuria. We used T-test, C hi square and binary logistic regression to evaluate means, frequency and correlation. $P$ values less than 0.05 were considered significant.

\section{Results}

The average age of patients was 12.9 years ( \pm 5.12 SD). Seventy-nine out of 108 patients had lymphoproliferative malignancies including leukemia $(n=59)$ and Iymphoma $(n=20)$. Twenty-nine had solid tumors which consisted of Wilms' $(n=14)$, neuroblastoma $(n=5)$, rhabdomyosarcoma $(n=5)$, retinoblastoma $(n=4)$ and yolk sac tumor $(n=1)$. The mean length of therapy was 35.44 months $( \pm 28.53$ SD). Treatment was discontinued for 52.48 months ( \pm 40 SD) on average. Table 1 shows the type, mean dosage and the number of recipient of chemotherapy drugs. A few patients were treated by I fosfamide or Platinum agents.

$7.5 \%$ of patients had GFR less than $90 \mathrm{ml} / \mathrm{min}$. $\mathrm{H}$ ypercalciuria and phosphaturia was observed in $7.2 \%$ and $13.5 \%$, respectively. M agnesuria was detected in $3.6 \%$ of patients. Three percent of patients had metabolic acidosis and metabolic alkalosis was seen in $10 \%$ of them.

U rine concentration defects were found in $19 \%$.
Proteinuria was detected in $7.2 \%$ of cases. Glycosuria was observed in $2 \%$. M icroscopic hematuria was found in $4 \%$, and $6 \%$ of patients had sterile pyuria with negative urine culture. $\mathrm{H}$ ypertension was detected in $8 \%$ of children. These renal dysfunctions were not correlated with the type of chemotherapy, sex, age of starting therapy, history of radiotherapy, nephrectomy, or administration of other nephrotoxic agents (Binary logistic regression, $\mathrm{P}>0.05$ ).

$25.2 \%$ of patients had more than one parameter of nephrotoxicity (13 of leukemia, seven of Iymphoma, three of Wilms' tumor, one of neuroblastoma, and two each of retinoblastoma and rhabdomyosarcoma). U sing binary logistic regression analysis, we found a correlation only between nephrotoxicity and Procarbazin (odd ratio 6.5, 95\% Confidence Interval 1.12-37.7, $\mathrm{P}=0.038$ ). The type of chemotherapy, age at start of therapy, sex, nephrectomy, radiotherapy, and use of other nephrotoxic agents showed no correlation with nephrotoxicity $(P>0.05)$.

\section{Discussion}

We have shown that there is some degree of renal dysfunction in long-term follow-up of children with a history of chemotherapy. This abnormality was not correlated with the type of chemotherapeutic drugs or the neoplastic disease. A minority of patients were treated by Ifosfamide or Platinum agents but onethird of cases generally had mild to moderate renal dysfunction.

A number of studies have been done on the longterm outcome of renal function in survivors of childhood cancer. The majority of studies are concerned with nephrotoxicity in the acute phase of therapy especially induced by Ifosfamide, Cisplatin and M ethotrexate. ${ }^{[3,5,7-11,13-15,17]}$

Reduction of glomerular filtration rate has been reported after completion of therapy in $13 \%$ of patients. ${ }^{[2,3,5,18-19]}$ $\mathrm{H}$ owever, this reduction of GFR is subclinical or mild and is detected by elevation of serum levels of Cystatin C, serum creatinine, or by iGFR (chromium EDTA). ${ }^{[1,3-4,17,19]} \mathrm{H}$ igh dose of $M$ ethotrexate, older age at the time of diagnosis, Wilms' tumor, and triple therapy (surgery, chemotherapy and radiation) have been reported as risk factors. ${ }^{[17,18]} \mathrm{N}$ one of these publications reported severe chronic renal failure and Koch $\mathrm{N}$ ogueira et al, observed that all long term survivors of osteosarcoma had GFR more than $80 \mathrm{ml} / \mathrm{min}$ despite receiving Ifosfamide, Cisplatin and $M$ ethotrexate. ${ }^{[3]} \mathrm{A}$ few of our patients showed mild reduction of GFR using the Schwartz formula; this effect was more 


\section{Table 1: Mean dosage of the chemotherapy drugs and the number of patients who were treated}

\begin{tabular}{|c|c|c|}
\hline Chemotherapy & $\begin{array}{c}\text { Number of } \\
\text { patients }\end{array}$ & $\begin{array}{c}\text { Mean dosage } \\
\left(\mathrm{mg} / \mathrm{m}^{2}\right)\end{array}$ \\
\hline Vincristine & 110 & 61 \\
\hline Actinomycin & 21 & 14802 \\
\hline Adriamycin & 44 & 152 \\
\hline Cyclophosphamide & 85 & 4423 \\
\hline Methotrexate & 66 & 3723 \\
\hline Etoposide & 15 & 1224 \\
\hline Ifosfamide & 5 & 11284 \\
\hline Prednisolone & 79 & 4545 \\
\hline Cisplatin & 8 & 380 \\
\hline VM26 & 7 & 1251 \\
\hline Camustine & 1 & 113 \\
\hline Cytarabine & 64 & 816 \\
\hline L-Asparaginase & 56 & 52503 \\
\hline Lanvis & 15 & 17771 \\
\hline DNR & 58 & 55 \\
\hline Lomustine & 1 & 62 \\
\hline Vinblastine & 9 & 32 \\
\hline Dacarbazine & 9 & 1541 \\
\hline MUSTIN & 9 & 25.4 \\
\hline Procarbazin50 & 6 & 1262 \\
\hline Bleomycin & 11 & 69 \\
\hline Mercaptopurine & 58 & 31139 \\
\hline Carboplatin & 3 & 2770 \\
\hline
\end{tabular}

prominent in those who received nitrogen mustard. Serum Cystatin C is more sensitive in detecting GFR changes compared to serum creatinine. ${ }^{[1,17]}$ Petal et al, showed that during chemotherapy iGFR had a value of $20 \%$ below GFR calculated by the Schwartz formula. ${ }^{[19]}$

Tubular dysfunction is more persistent after chemotherapy has ended, and dysfunction of the organic anion transporter has been suggested as the probable mechanism. ${ }^{[2]}$ In our study the urinary concentration defect was generally followed by phosphaturia and hypercalciuria. Detection of metabolic acid-base disorders, tubular proteinuria, glycosuria and diluted urine might suggest involvement of different parts of the nephron. No risk factor was detected for this tubular dysfunction but impaired urinary concentration was pronounced in those with solid tumors. Similar disorders have been reported in the literature. ${ }^{[1,3,5]} \mathrm{K}$ veder et al, found normal fractional excretion of sodium, potassium, calcium and phosphate after 22 years followup on average. The urinary $\mathrm{N}$-acetyl-B-glucosaminidase (NAG) / creatinine ratio was highest in those patients who received triple therapy. ${ }^{[18]}$ Proteinuria was more frequent in Kopecna's study on survivors of acute lymphoblastic leukemia. ${ }^{[4]}$ These reports may suggest proximal tubular dysfunction. Phosphaturia, calciuria, and metabolic acidosis made the children prone not only to osteoporosis but also to urolithiasis. ${ }^{[20-22]} \mathrm{N}$ one of our patients had nephrolithiasis in renal sonography and another project is being conducted to evaluate bone densitometry in late survivors.

$\mathrm{H}$ ypertension has been reported as a late sequel of radiotherapy due to renal artery stenosis. ${ }^{[23]} \mathrm{H}$ owever, only $1.6 \%$ of all hypertensive patients in our group had a history of receiving radiotherapy. Acrolein, a metabolite by-product of Cyclophosphamide and Ifosfamide, may cause hemorrhagic cystitis and bladder fibrosis and increase the risk of developing bladder cancer. ${ }^{[24-26]}$ O nly $4 \%$ of those who received $\mathrm{N}$ itrosourea had microscopic hematuria. Because of an insufficient number of cases, we could not find any correlation between hematuria and those therapies.

Few studies have been done about the overall incidence of nephrotoxicity in the survivors of chemotherapy. Putting all of the parameters together, one third of our patients showed mild to moderate nephrotoxicity independent of any risk factors. This finding shows the subclinical renal dysfunction in our survivors in whom its consequences must be determined.

In conclusion, mild to moderate tubular dysfunction has been observed in survivors of chemotherapy. Routine follow-up care of renal function is recommended.

\section{Acknowledgment}

The authors thank Mrs. Pooran Jodar for performing laboratory analysis.

\section{References}

1. Bardi E, Olah AV, Bartyik K, Endreffy E, Jenei C, Kappelmayer J, et al. Late effects on renal glomerular and tubular function in childhood cancer survivors. Pediatr Blood Cancer 2004;43:668-73.

2. Kakihara T, Imai C, Hotta H, Ikarashi Y, Tanaka A, Uchiyama M. Impaired tubular excretory function as a late renal side effect of chemotherapy in children. J Pediatr Hematol Oncol 2003;25:209-14.

3. Koch Nogueira PC, Hadj-Aissa A, Schell M, Dubourg L, BrunatMentigny M, Cochat P. Long-term nephrotoxicity of cisplatin, ifosfamide and methotrexate in osteosarcoma. Pediatr Nephrol $1998 ; 12: 572-5$

Indian Journal of Cancer | October-December 2008 | Volume 45 | Issue 4 
4. Kopecna L. Late effects of anticancer therapy on kidney function in children with acute lymphoblastic leukemia. Bratisl Lek Listy 2001; 102:357-60.

5. Skinner R. Chronic ifosfamide nephrotoxicity in children. Med Pediatr Oncol 2003;41:190-7.

6. Schwartz CL. Long-term survivors of childhood cancer: The late effects of therapy. Oncologist 1999;4:45-54.

7. Aleksa K, Woodland C, Koren G, Young age and the risk for ifosfamide-induced nephrotoxicity: A critical review of two opposing studies. Pediatr Nephrol 2001;16:1153-8.

8. Skinner R, Pearson AD, English MW, Price L, Wyllie RA, Coulthard MG, et al. Risk factors for ifosfamide nephrotoxicity in children. Lancet 1996;348:578-80

9. McCune JS, Friedman DL, Schuetze S, Blough D, Magbulos M, Hawkins DS. Influence of age upon Ifosfamide-induced nephrotoxicity. Pediatr Blood Cancer 2004;42:427-32.

10. English MW, Skinner R, Pearson AD, Price L, Wyllie R, Craft AW. Dose-related nephrotoxicity of carboplatin in children. $\mathrm{Br} J$ Cancer 1999;81:336-41.

11. Erdlenbruch B, Pekrum A, Roth C, Grunewald RW, Kern W, Lakomek $\mathrm{M}$, Cisplatin nephrotoxicity in children after continuous 72-h and 3x1-h infusions. Pediatr Nephrol, 2001;16:586-93.

12. Hanigan MH, Devarajan P. Cisplatin nephrotoxicity: Molecular mechanisms. Cancer Ther 2003;1:47-61.

13. Lee BS, Lee JH, Kang HG, Hahn H, Lee JH, Shin HY, et al. Ifosfamide nephrotoxicity in pediatric cancer patients. Pediatr Nephrol 2001; 16:796-9.

14. Loebstein R, Koren G. Ifosfamide-induced nephrotoxicity in children: Critical review of predictive risk factors. Pediatrics 1998; 101:E8.

15. Rossi RM, Kist C, Wurster U, Kulpmann WR, Ehrich JH. Estimation of ifosfamide / cisplatinum-induced renal toxicity by urinary protein analysis. Pediatr Nephrol 1994;8:151-6.

16. Safirestein RL. Renal diseases induced by antineoplastic agents. In: Schrier RW, editor. Diseases of the kidney and urinary tract. 7th ed. Philadelphia: Lippincott, Williams and Wilkins; 2001. p. 1175-88.

17. Gronroos M, Jahnukainen T, Mottonen M, Perkkio M, Salmi TT. Renal side effects induced by high dose methotrexate treatment. Pediatr Blood Cancer 2006;47:490-1.

18. Kopecna L. Late effects of anticancer therapy on kidney function in children with acute lymphoblastic leukemia. Bratisl Lek Listy 2001; 102:357-60.

19. Kveder R, Jereb B, Dremelj M. Late consequences on renal function in long term childhood cancer survivors. Pediatr Blood Cancer 2006;47:495-6.

20. Asadi-Pooya AA, Karamizadeh Z, Rahiminejad M, Shahriari M, Karimi M. Disturbances in calcium metabolism in childhood lymphoblastic leukemia, before and after chemotherapy. Irn J Endocrinol Metab 2003;5:211-4.

21. Davies JH, Evans BA, Jenney ME, Gregory JW. Skeletal morbidity in childhood acute lymphoblastic leukaemia. Clin Endocrinol 2005;63:1-9.

22. Howard SC, Kaplan SD, Razzouk BI, Rivera GK, Sandlund JT, Ribeiro $\mathrm{RC}$, et al. Urolithiasis in pediatric patients with acute lymphoblastic leukemia. Leukemia 2003; 17:541-6.

23. Dewit L, Anninga JK, Hoefnagel CA, Nooijen WJ. Radiation injury in the human kidney: A prospective analysis using specific scintigraphic and biochemical endponits. Int J Radiat Oncol Biol Phys 1990; 19:977-83.

24. Levine LA, Richie JP. Urological complications of cyclophosphamide. J Urol 1989; 141:1063-9.

25. Samra Y, Hertz M, Lindner A, Urinary bladder tumors following cyclophosphamide therapy: A report of two cases with a review of the literature. Med Pediatr Oncol 1985; 13:86-91.

26. Sarosy G, Ifosfamide - pharmacologic overview. Semin Oncol $1989 ; 16: 2-8$.

\section{Author Help: Reference checking facility}

The manuscript system (www.journalonweb.com) allows the authors to check and verify the accuracy and style of references. The tool checks the references with PubM ed as per a predefined style. Authors are encouraged to use this facility before submitting articles to the journal.

- The style as w ell as bibliographic elements should be $100 \%$ accurate to get the references verified from the system. A single spelling error or addition of issue number / month of publication will lead to error to verifying the reference.

- Example of a correct style

Sheahan P, O'leary G, Lee G, Fitzgibbon J. Cystic cervical metastases: Incidence and diagnosis using fine needle aspiration biopsy. Otolaryngol Head Neck Surg 2002;127:294-8.

- Only the references from journals indexed in PubM ed would be checked.

- $\quad$ Enter each reference in new line, without a serial number.

- Add up to a maximum 15 reference at time.

- If the reference is correct for its bibliographic elements and punctuations, it will be shown as CORRECT and a link to the correct article in PubMed will be given.

- If any of the bibliographic elements are missing, incorrect or extra (such as issue number), it will be shown as INCORRECT and link to possible articles in PubM ed will be given. 